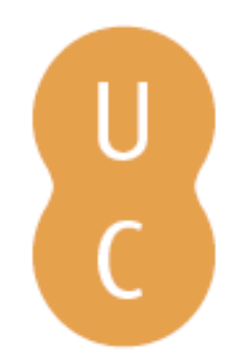

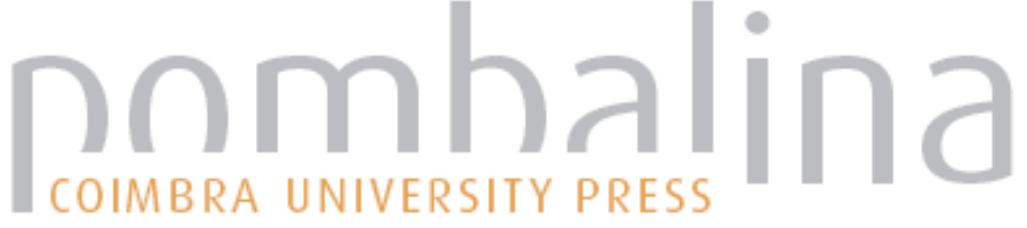

\section{Os monstros no Naturalismo}

Autor(es): $\quad$ Mourão, José Augusto; Guedes, Maria Estela

Publicado por: Imprensa da Universidade de Coimbra

URL

persistente:

URI:http://hdl.handle.net/10316.2/32342

DOI:

DOI:http://dx.doi.org/10.14195/978-989-26-0362-9_20

Accessed : $\quad$ 26-Apr-2023 08:10:08

A navegação consulta e descarregamento dos títulos inseridos nas Bibliotecas Digitais UC Digitalis, UC Pombalina e UC Impactum, pressupõem a aceitação plena e sem reservas dos Termos e Condições de Uso destas Bibliotecas Digitais, disponíveis em https://digitalis.uc.pt/pt-pt/termos.

Conforme exposto nos referidos Termos e Condições de Uso, o descarregamento de títulos de acesso restrito requer uma licença válida de autorização devendo o utilizador aceder ao(s) documento(s) a partir de um endereço de IP da instituição detentora da supramencionada licença.

Ao utilizador é apenas permitido o descarregamento para uso pessoal, pelo que o emprego do(s) título(s) descarregado(s) para outro fim, designadamente comercial, carece de autorização do respetivo autor ou editor da obra.

Na medida em que todas as obras da UC Digitalis se encontram protegidas pelo Código do Direito de Autor e Direitos Conexos e demais legislação aplicável, toda a cópia, parcial ou total, deste documento, nos casos em que é legalmente admitida, deverá conter ou fazer-se acompanhar por este aviso. 
Ana Leonar Pereira Jםão Rui Pita [ Coordenaçä̃ ]

\section{Miguel Bomberda e as singularidades de uma época}

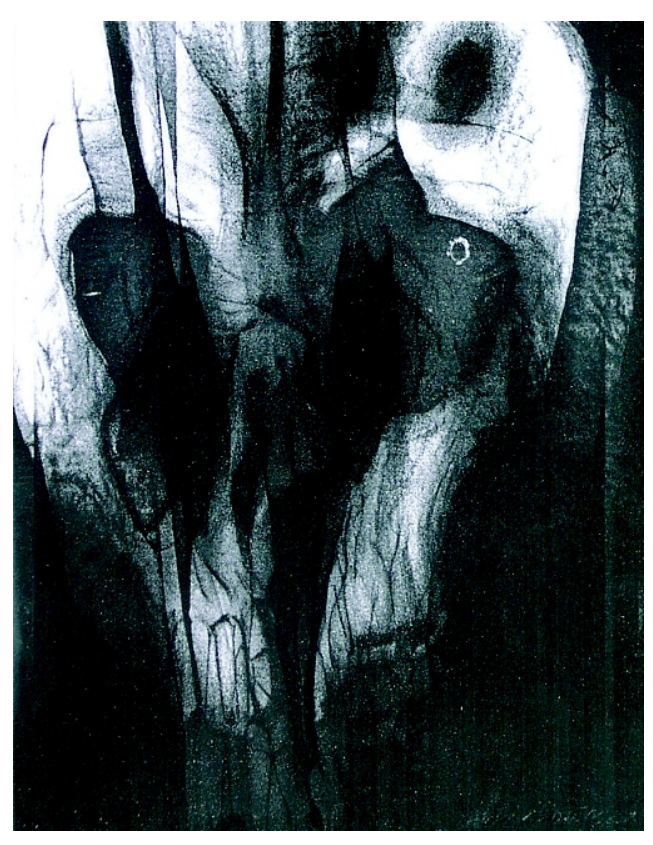


(Página deixada propositadamente em branco) 
Ana Leonor Pereira

João Rui Pita

(Coordenação)

\title{
FOLHA DE ROSTO
}

\author{
Miguel Bombarda (1851-1910)
}

a as singularidades de uma época 


\section{Coordenação Científica da Colecção Ciências e Culturas}

João Rui Pita e Ana Leonor Pereira

Os originais enviados são sujeitos a apreciação científica por referees

\section{Coordenação Editorial}

Maria João Padez Ferreira de Castro

\section{Edição}

Imprensa da Universidade de Coimbra

Email: impresauc@ci.uc.pt

URL: http://www.imp.uc.pt • Normas de publicação de colecções

Design

António Barros

Pré-Impressão

António Resende

Imprensa da Universidade de Coimbra

Capa

António Dantas. Sem título, 2002. Col. António Barros. Coimbra

Impressão e Acabamento

SerSilito • Maia

\section{ISBN}

978-989-8074-11-9

\section{Depósito Legal}

Obra publicada com a colaboração de:
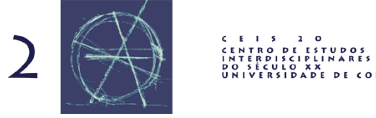

Obra publicada com o apoio de:

FCT Fundação para a Ciência e a Tecnologia

MINISTÉRIO DA CIÊNCIA, TECNOLOGIA E ENSINO SUPERIOR Portugal

Programa Operacional Ciência, Tecnologia, Inovação do Quadro Comunitário de Apoio III

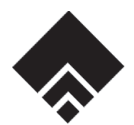

Fundaçāo Eng. António de Almeida

(C) Agosto 2006, Imprensa da Universidade de Coimbra 
José Augusto Mourão* ; Maria Estela Guedes**

* Faculdade de Ciências Sociais e Humanas, Universidade Nova de Lisboa, Portugal

** Centro Interdisciplinar de Ciência, Tecnologia e Sociedade da Universidade de Lisboa, Portugal

\title{
Os Monstros no Naturalismo
}

"Monstra vero per excessum sunt».

D. Vandelli

"É extremamente difícil senão impossivel definir

o que seja um individuo normal»

J. A .Pires de Lima

\begin{abstract}
«L'imaginaire a cette caractéristique d'abhorrer les frontières nettes, les objets bien délimités dans leur apparence. Quoi de plus concret qu'une pierre, forme saillante permanente s'il en fut? C'est pourquoi la pensée rationnelle s'efforce de ramener la propagation des prégnances à des constructions combinatoires de formes saillantes: réduire l'imaginaire au symbolique, tel est son idéal, réduire toute propagation à une construction de solides, comme l'enfant avec un jeu de cubes (et le démiurge du Timée n’en était pas si loin)».
\end{abstract}

René Thom

«Observatio diuturna, notandis rebus, fecit artem», dixit Cicero num livrinho que se intitula De divinatione Liber II. Essa passou a ser a divisa do Instituto de Anatomia da Faculdade de medicina do Porto que se tornou, ao tempo de J. A. Pires de Lima um centro de estudos de teratologia descritiva. A divisa da biblioteca Regenstein da Universidade de Chicago não anda muito longe do «espírito» que preside às Associações de Filosofia Natural: «Onde o crescimento cresce, a própria vida se alarga, clarificada e amelhorada». Não obstante isso, o obscurantismo e a ignorância convivem bem com essa forma subtil de vontade de poder dissimulada na forma mais sincera da humildade - aquilo a que chamamos o desejo de verdade. O fantasma da inquisição é a pureza da fé. Que destino tiveram os judeus e os ciganos, mas também os atrasados mentais e outras criaturas consideradas como desvios à «raça pura»? Onde nos levara o horroroso culto da uniformização em que todos temos de corresponder a um formato? Que fazer do conceito biométrico de anomalia, ou do conceito estatístico de normalidade? 
A que fantasma serve a ciência? De que «vida» se ocupa? Que formas de eugenismo dissimula? ${ }^{1}$ Não teremos entrado há muito na projecção aterrorizadora de uma forma de eugenismo, não ideológico - aquele que designaria categorias de pessoas que não merecem viver - mas técnico? Não se terá a técnica deparado da ciência que servia a Vida que fala em verdade? Não estará o próprio discurso ético a alinhar-se com o discurso técnico, sob pretexto de caridade: fazer as coisas o melhor possível? ${ }^{2}$

\section{Fenómenos saturados}

É verdade. Para ver basta ter olhos. Olhar exige muito mais: e necessário discernir o visível de si próprio, distinguindo nele planos em profundidade e em largura, delimitar formas, observar mudanças e seguir movimentos. Olhar acaba por ser impor objectivos ao visível e, pouco a pouco, a fazer dele objectos. Em Filosofia fala-se de fenómenos saturados e de fenómenos comuns ${ }^{3}$. Um fenómeno é o encontro entre uma percepção sensível e uma significação. Na maioria dos casos temos significações verificadas apenas e parcialmente através das intuições sensíveis (ex. do automobilista comum que tem um conceito relativo do seu carro, não um conceito total, como aquele que o concebeu). Mas nos temos também a experiência de determinados fenómenos que não são correntes, que podem acontecer, mas raramente, em que o dado intuitivo superabunda (quando se ama ou sofre, etc.). Esse é um caso de fenómeno saturado, e a maior dificuldade está no encontro de fenómenos intuitivos cujo sentido se ignora. São casos em que a dificuldade resulta do atraso do conceito sobre o dado sensível. A ideia de fenómeno saturado conota o excesso da intuição sobre a significação ou o conceito, o que deixa crer que este género de fenómeno não se deixa subssumir sob a categoria geral do objecto. $\mathrm{O}$ acontecimento dá-nos o mundo na sua quantidade imprevisível, o ídolo dá-nos o visto na sua intensidade insuportável, a carne dá-me a mim mesmo na minha absolutidade, o ícone dá-me a outrem ma sua alteridade «irregardable». Claude Bernard afirmava que «qualquer manifestação dum fenómeno no ser vivo esta necessariamente ligada a uma destruição orgânica» ${ }^{4}$. $\mathrm{O}$ monstro e aquilo que não cabe no corpo identitário moderno, como hoje o «cyborg» remete para a utopia de uma «imagem condensada da imaginação e da realidade material que conjuntamente estruturam toda a possibilidade de transformação histórica» 5 .

\footnotetext{
${ }^{1} \mathrm{O}$ nazismo, como sublinha G. Agamben, fará da vida nua do homo sacer, definida em termos biológicos e eugénicos, o lugar de uma decisão incessante sobre o valor e a ausência de valor, onde a biopolítica se transforma continuamente em tanatopolítica (G. Agamben, O poder soberano e a vida nua, Presença, 1998, p. 146.

${ }^{2}$ M. Barbosa Sueiro fala a propósito da anatomia de «finalidade utilitária - mas de virtuoso utilitarismo» (Sueiro, 1950, 26).

3 Jean-Luc Marion, De surcroit, PUF, 2001, p. 61, p. 121.

${ }^{4}$ Claude Bernard, Leçons sur les phenomenes de la vie communs aux vegetaux et aux animaux, Paris, Vrin, 1966.

${ }^{5}$ Estou a parafrasear o Manifesto Cyborg de Donna Haraway, amplamente disponivel na Internet.
} 


\section{Abdução}

A ciência só e tal qual e para cientistas tais quais são: inchados, ressentidos, deterministas, positivistas ${ }^{6}$. Desde Bacon que se pensa que a imaginação é também criadora de teorias que a observação e a experiência confirmam. E verdade que o sentido esta sempre pressuposto desde que se começa a falar. Podemos canalizar todos os enunciados sob a tutela dum paradigma cuja sintaxe e legitimada pelas suas condições de verdade. Ou pode-se apreender o sentido no ponto em que o paradoxo e o sem sentido se confrontam com o bom senso e o senso comum, como sinais de que e necessário dar lugar a outras dimensões da expressão. C. S. Peirce definiu a abdução como o processo de inovação de sentido e de referência ao nível da hipótese constitutiva de uma teoria:

"A abdução é o processo de formação de uma hipótese explicativa. É a única operação lógica que introduz uma nova ideia; porque a indução nada faz senão determinar um valor, e a dedução envolve meramente as consequências necessárias de uma hipótese pura." (Peirce, 1934: V; ver também 106)

Nesse sentido, a ciência deveria combinar diversos instrumentos: «(...) concebemos naturalmente a ciência como tendo três tarefas: (I) a descoberta de Leis, que é conseguida pela indução; (2) a descoberta de Causas, que é conseguida pela inferência hipotética; (3) a predição de Efeitos, que é conseguida pela dedução" (Peirce, cit. in Apel, 1981: 103-104). Dado que a verdade da dedução é condicionada pela verdade das premissas, e a indução meramente determina as grandezas, é a abdução que introduz novas ideias e determina as inferências probabilísticas. A abdução descreve ainda um acto de iluminação, um flash: a "súbita ideia» de Newton, a leitura de Malthus por Darwin ou ainda a sua analogia definindo a hipótese de descendência comum, a «iluminação» de Poincaré, a «ideia fecunda» de Claude Bernard (Stengers, Schlanger, 1991: 70).

Um modelo de interacção considera a legitimidade de três processos de crescimento do conhecimento - indução, dedução e abdução - e tal comparação apresenta uma solução que anula o paradoxo de Hume: «(...) a indução sem abdução é cega, a abdução sem indução é vazia (...) (Apel, 1968: 89). Esta visão é responsável por modificações revolucionárias na ciência, e confirma o papel essencial da inovação metafórica. A própria evolução do evolucionismo darwinista é um exemplo destes processos, dos que o seu estatuto científico mudou a partir do momento em que assimilou as leis de Mendel - que foram uma novidade definida numa disciplina diferente e modificando o mapa das experiências tradicionais e inconclusivas dos botânicos com a hibridação (Bertalanffy, 1952: 69): a abdução transformou a botânica e depois a sua retranscrição metafórica na biologia definiu o programa neo-darwinista. Nesse sentido, a abdução não é mais do que uma nova designação para a escolha das metáforas, ou das hipóteses iniciais, que é essencial em qualquer teoria. $\mathrm{Na}$ astronomia, considera-se que

\footnotetext{
${ }^{6}$ António Manuel Baptista, O Discurso Pós.Moderno Contra a Ciência. Obscurantismo e irresponsabilidade, Gradiva, 2002.
} 
a descoberta da órbita de Marte por Kepler é um exemplo deste tipo de processos (Apel, 1968: 88-89).

\section{Anatomia de casos}

A medicina dita oficial, universitária e subsidiada pelo Estado, continua a reivindicar para ela só ao mesmo tempo a cientificidade e o reconhecimento oficial. A medicina oficial desenvolveu sobremodo a racionalidade segundo fins, a razão eficaz que se propõe objectivos e inventa os meios para os realizar. E nisso ela esta conforme ao imperativo essencial da modernidade. Não saímos ainda dessa visão dualista. E. Landowski escreve, a este propósito: «o gabinete medico, lugar de um saber cada vez mais sofisticado, aparece paradoxalmente, em razão do imobilismo conceptual que nele se vê perdurar, como o santuário do positivismo mais sumario e mais retrogrado» ${ }^{7}$. Pires de Lima (1937) assaca a Descartes erros grosseiros (fantasias cartesianas), este por exemplo com imensa voga na filosofia biológica: a localização na glândula pineal da alma humana. Trata-se do mesmo «erro de Descartes» sobre que escreve António Damásio?

Como já escrevi algures, "O monstro reflecte sempre uma determinada ordenação do mundo, seja este natural ou cultural. Eles são a ruptura da ordem em que cristalizam valores sociais e formas de conhecimento. Produz sentimentos e reacções contraditórias: medo, temor, asco, mas também prazer e lubricidade. Parte às vezes de uma cultura demonológica, outras vezes representação do exótico, do desconhecido, do estranho. Ou se manifesta de forma lúdica (lusus naturae), carnavalesca, ou transporta consigo o estigma da admonição (Deus Irae). O monstro não é só o negativo de formas variadas, mas também de graus diferentes de civilidade. Ambíguo, portanto» ${ }^{8}$. $\mathrm{O}$ recurso a Antiguidade tem aqui alguma pertinência. A definição aristotélica de monstro (teras): «Alias aquele que não se parece com os pais e já, de certa maneira, um monstro porque, neste caso, a natureza se afastou do tipo genérico» ${ }^{9}$. Um andrógino e um prodígio que publicamente deve ser exposto como sinal maléfico que o Estado deve fazer desaparecer. Passou-se a outra atitude: interpretar o fenómeno como um erro da natureza, uma má-formação anatómica rara, mas explicável. Os seres dotados dos dois sexos serão vistos como um jogo da natureza, e o que Plínio o Velho explicitamente diz. A bixexualidade foi recebida primeiro como monstruosidade, ameaça, depois como fenómeno explicável e finalmente tolerado, recuperado como um «bem» de consumo ${ }^{10}$.

Há monstros duplos. Há um monstro duplo humano do género esternópago, em que os dois fetos tem lábio leporino (Pires de Lima, 1941). Há casos de ectrodactilia,

\footnotetext{
${ }^{7}$ Eric Landowski, «Fronteiras do corpo», in RCL, Maio de 2001, no 29, p. 273.

${ }^{8}$ Jose Augusto Mourao, "Anjos e mutantes: o hibridismo apocaliptico», in Cadernos ISTA, no 8, 1999. p. 99.

${ }^{9}$ Aristoteles, Generation des animaux IV 2, 767b.

${ }^{10}$ Cf. Luc Bisson, Le sexe incertain. Androgynie et hermaphroditisme dans l'Antiquite Greco-romaine, Ed. EDDIF, Casablanca, 1992.
} 
não apenas na lenda. Há uma santa barbada (Pires de Lima, 1916), prova de que, segundo Zacuto, «Faeminae ergo in viros verti possunt». Não é para Le Double a nossa península a região mais fértil em mulheres barbadas? Há o caso da ectrodactilia na lenda que J. A. Pires de Lima (1919) analisa. ${ }^{11}$ Ou o caso de polidactilia transitoria sobre que o mesmo cientista escreve ${ }^{12}$. Ou ainda dois casos de polimastia ${ }^{13}$. Há o monstro fêmea, com duas cabeças, uma só vulva, dois orifícios anais, dois braços e duas pernas que J. A. Pires de (1925) estuda ${ }^{14}$.Há inúmeros casos de hermafroditismo e intersexualidade. Mas há também o erro e a impostura teratológica, por exemplo a do "Galo-fenómeno" que apresentava dois longos cornos implantados na cabeça e que Pires de Lima se diverte a depenar, sacrificando a seguir um outro para verificar que os seus órgãos sexuais eram masculinos. Há o bacorinho monstruoso que nasceu com mais dez bacorinhos vivos e viáveis. Há a fusão de duas cabeças e independência da parte posterior de dois indivíduos que o Prof. Julin analisa. Há o reducionismo de Lombroso que conclui que em pelo menos em certa classe de criminosos havia numerosos estigmas morfológicos que distinguiam os delinquentes dos indivíduos normais.

A norma anatómica (Sueiro, 1950) faz lei. "Monstra vero per excessum sunt», escreve Vandelli (1776). Porém, o normal foi sempre a crux da ciência. O híbrido foi sempre a ameaça, apesar do que diz Simon Mawer: "A mestiçagem é um bom princípio. O que há de melhor não é o que é híbrido? Os melhores cães - e tenho a certeza - são os vira-latas» ${ }^{15}$. Em que outro lugar a imaginação tem maior entrada do que este? As normas são essenciais aos discursos que animam a vida social. A sua constituição esquemática explica o impacto afectivo que acompanha a sua aparição discursiva. A norma parece exigir uma boa distância, da parte das ocorrências que ela avalia, e que não devem tomar o seu lugar. As normas manifestam uma sensibilidade dupla, correspondendo a uma topologia com duas entradas (pouco/assaz/demasiado), que regula os comportamentos aproximativos, nomeadamente a imprecisão exigida, de todos os fenómenos normativos, do domínio da gramática ao da jurisdição. Mas, em último caso, na norma trata-se da estabilização do imaginário através da referência ao semelhante, mecanismo que caracteriza a identificação categorial e analógica (P. A. Brandt). Não obstante, mesmo entre cientistas o conceito de norma esta sujeito a discussão. Carlos May Figueira (1864) considera impossível aceitar a ideia de Pareo (1633) segundo a qual haveria hermafroditas com dupla aptidão geradora. Geoffroy Saint-Hilaire (fundador da teratologia em bases científicas) tem a melhor classificação:

${ }^{11}$ Arquivos de História da Medicina Portuguesa, Porto, nova série, ano 10 (3): 6 pp.

12 J.-A. Pires de Lima (1920) - Polydactilie transitoire. Extrait des Comptes rendus des séances de la Société de Biologie, LXXXIII, p. 190.

${ }^{13}$ Deux cas de polymastie. Extrait de la Gazette Médicale du Centre. Tours, Imprimerie Tourangelle, 12 pp.

${ }^{14}$ J.-A. Pires de Lima, Le grand pectoral chez les monstres doubles. Extrait de Comptes Rendus de l'Association des Anatomistes (Vingtième réunion, Turin, 6-8 avril 1925), Éditions Médicales, Paris, 6 páginas.

${ }^{15}$ Simon Mawer, «Freaks», Pública, 3 de fevereiro de 2002. 
«hermafroditas com excesso e sem excesso) ${ }^{16}$. Para Luís Guerreiro (1921) o corpus da anatomia é o corps - cadáver. No entanto a anatomia é considerada ramo da Biologia. A anatomia faz descriçôes-tipos sem olhar às modificações somáticas que os indivíduos podem sofrer, provocadas pelas inúmeras contingências que moldam a matéria viva: «Estas descrições tipos correspondem a hipotéticos indivíduos normais; qualquer outra disposição, não incluída nessas descrições, na mesma letra dos tratados de anatomia e conforme eles, ou constitui uma anomalia, que pode ser grande ou pequena, ou uma variação, anomalia ou monstruosidade, segundo a sua aparência. A adoptar-se este modo de ver, certamente nos sujeitaríamos à contingência de concluir que o homem normal, quer dizer, aquele que corresponde à descrição dos autores, é um homem que não existe! A própria normalidade seria, assim, privativa dos tratados (...)». O autor não aceita o esquema em nome do transformismo, pois os conceitos de anomalia, etc., só seriam válidos em espécies imutáveis. Vale o mesmo para a definição de monstro de E. Rabaud e de normal e anormal de Rosenberg. Acaba por se substituir o termo anomalia por variação ${ }^{17}$.

\section{Coda}

Agamben, ao fazer a genealogia do conceito de vida, conclui que em toda a medicina grega não há um conceito médico-científico, como se pensa, mas um conceito filosófico-político. "O homem é o ser vivo que não tem nenhuma vocação biológica, histórica, etc. É um ser de potência que não se identifica com nenhuma figura determinada» ${ }^{18}$. É fácil identificar um monstro. É fácil idealizar a forma humana, as suas variações musculares. Para o naturalista a vida não tem mistérios, tão bem ele vê, tão bem educou o senso crítico. Não será então necessário bem ver para melhor compreender? Se não podemos negar ao corpo medical uma existência histórica, cientifica ou ideológica, e pelo menos necessário reconhecer que esse corpo não é todo o corpo (quer dizer o todo duma imaginação do seu real) e trabalhar pelo menos com o mínimo de imaginário com que Valery tentava descobrir nele funçóes figurativas, ordens fantasmáticas.

Todo o discurso medical contemporâneo, higienista e moral, de que as bonecas de Pierre Spitzner são uma espécie de caricatura, apoia-se num catálogo desordenado das aberraçôes de imagens do corpo ${ }^{19}$. Para lá das aberrações iconológicas, é necessário notar que a «escrita» medica não tende a fazer significar algo ao corpo. E não se esqueça o seguinte: «From the point of view of the subject, the representation of the body,

${ }^{16}$ Carlos May Figueira (1864) - Observação de um caso de hermaphrodismo masculino colhida no Hospital de S. José. Imprensa Nacional, Lisboa, p. 11.

${ }^{17}$ Luís Guerreiro (1921) - Sobre a doutrina e a escola anatómica do Prof. H. de Vilhena. Instituto de Anatomia da Universidade de Lisboa. Arquivo de Anatomia e Antropologia, VII, 38 p. 1.

18 "A política deve ser orientada para a ideia de felicidade», Entrevista de António Guerreiro in Expresso 8 Novembro 1997, p. 26.

${ }^{19}$ Jean Louis Schefer, Choses écrites. Essais de literature et à peu près, Paris, POL, 2000, p. 169. 
even when narrowly biological, is always an image of the self: identity, genealogical resemblance, cultural norm and configuration, etc. $»^{20}$.

Há muito que o corpo feminino deixou de ser o duma deusa (Diana ou Helena), aparecendo associado ao disforme, a gorgona, como os corpos disformes da pintura de Jenny Saville. Os corpos de Saville são uma superfície sem fundo, pura pele, como este Híbrido (1977), uma obra em que Saville nos oferece uma visão do corpo recomposto a base de fragmentos de outros corpos. ${ }^{21}$ Como estamos longe do «Estudo de anatomia artística» em que Pires de Lima (1944) estuda a exuberante musculatura (em especial o deltóide) do Negro ou do Pescador ou de Afonso Henriques de Soares dos Reis! O movimento naturalista na Arte tem de facto uma profunda influencia na anatomia. Mas o ponto de vista da anatomia ao estudar as variaçôes do deltóide e considerar essas variações como anomalias. A conclusão é elucidativa: «Um verdadeiro artista não copia a natureza como um fotógrafo. Interpreta, idealiza, mas nunca deturpa os factos. Quando vejo certas esculturas modernas com a musculatura deformada, convenço-me que o Artista não se guiou pelo que viu, mas antes pela sua fantasia» ${ }^{22}$. E todavia, haverá, no discurso dos saberes, discurso mais marcado por uma espécie de regularidade do fantasma (o do corpo como objecto, como labirinto, etc.) do que o discurso da medicina?

\section{Corpus teratológico}

Está em linha uma terato-exposição, "A Norma e o Monstro», em http://www.triplov.com/monstros, que constitui uma das fontes deste trabalho, com textos dos dois autores e concepção de Maria Estela Guedes (webmaster).

FigueIRA, Carlos May (1864) - Observação de um caso de hermaphrodismo masculino colhida no Hospital de S. José. Imprensa Nacional, Lisboa, 22 pp..

Guerreiro, Luís (1921) - Sobre a doutrina e a escola anatómica do Prof. H. de Vilhena. Instituto de Anatomia da Universidade de Lisboa. Arquivo de Anatomia e Antropologia, VII, 38 pp..

LiMA, J. A. Pires de (1916) - Uma santa barbada (A propósito da lenda de Santa Vilgeforte). Separata dos Arquivos de História da medicina Portuguesa, (VII), 1, 14 pp..

Lima, J. A. Pires de (1919) - A ectrodactilia na lenda. Arquivos de História da Medicina Portuguesa, Porto, nova série, ano $10(3): 6 \mathrm{pp}$.

Lima, J. A. Pires de (1937) - Primeiro: ver. Extracto de Trabalhos da Associação da Filosofia Natural, I (3), 16 pp., fotos.

Lima, J. A. Pires de (1938) - Os Monstros ônfalositos. Boletim da Associação da Filosofia Natural, I (1) $1-24$.

LimA, J.-A. Pires de (1940) - Monstros ciclocefalianos. Separata de Folia Anatomica Universitatis Conimbrigensis, XIII (2), 28 pp.

\footnotetext{
${ }^{20}$ Olivier Abel, «The Human Subject in Image of a Body», Diogenes, no 172, Vol. 43/4, Winter 1995, p. 55.

${ }^{21}$ Veja-se Tonia Raquejo, "Sobre lo Monstruoso. Un paseo por ele amor y la muerte», in Esteticas del arte contemporaneo, (ed. ) Domingo Hernandez Sanchez, Universidad Salamanca, 2002, p. 71.

${ }^{22}$ J. A. Pires de Lima, «Estudo de anatomia artística. Variação muscular numa escultura de Soares dos Reis», Porto, Enciclopédia Portuguesa, Limitada, 1944, p. 20.
} 
LiMA, J. A. Pires de (1941) - Novos subsídios para o estudo dos monstros duplos. Extracto dos Anais da Faculdade de Ciências do Porto, XXVI, 12 pp..

LimA, J. A. Pires de (1944) - Estudo de anatomia artística - variação muscular numa escultura de Soares dos Reis. Associação Portuguesa para o Progresso das Ciências Médicas e Biológicas. Enciclopédia Portuguesa, Limitada, Porto. 22 pp..

Sueiro, M.B. (1950) - Conceito de normalidade em anatomia humana. Arquivo de Anatomia e Antropologia, XXVII: 401-409.

Vandelli, D. (1776) - Dissertatio de Monstris. Ex Typographia Academico Regia, Colimbriae. 8 pp. 2 estampas.

Resumo - Exorcizar a transcendência do domínio político ou científico é um programa comum a Hobbes e a Boyle. Já então, ou era o Estado - reduzido ao papel de Actor - ou o laboratório - um não-humano - que arbitravam sobre a "coisa pública» ou sobre matters of fact. Os prodígios aterradores do hermafroditismo, a inter-sexualidade, a santa barbada, os monstros duplos deixam de ser vistos como caprichos da natureza ou da mitologia - inexplicáveis -, passando a ser analisados como más-formações anatómicas - explicáveis. Analisam-se textos e iconografia do monstro, tal como é visto no naturalismo, e de modo particular na medicina. O conceito de normalidade em anatomia humana é um conceito central neste domínio. O monstro, ao colocar problemas antigos: o das fronteiras do normal e do anormal, do puro e do impuro, é um atentado à natureza enquanto disformidade, mas controlável pela ciência, desde que agrilhoado no conceito de variação própria do transformismo, ou do desvio à norma estatística - o que nos deixa a todos matematicamente sossegados.

Abstract - To exorcise transcendence from the political or scientific domain is a common programme to Hobbes and Boyle. At that time, it was already the State (reduced to the role of Actor) or the laboratory (a non-human) that had the control over the 'public thing' or over matters of fact. The terrorizing prodigies of hermaphroditism, inter-sexuality, the bearded saint, and double monsters were no longer seen as inexplicable freaks of nature or mythology, and began to be understood as explicable anatomic malformations. Texts and the iconography of the monster as it was seen in naturalism, and particularly in medicine, are analysed. The concept of normality in human anatomy is a central concept in this domain. By raising old problems - such as the frontier between what is normal and what is abnormal, what is pure and what is impure -, the monster as deformity is an attack against nature, but it is controllable through science as long as it is chained to the concept of variation that is proper to transformism or to the concept of deviation from the statistical norm - what makes us all mathematically undisturbed. 
(Página deixada propositadamente em branco) 


\section{Colecção \\ Ciências e Culturas \\ Cuimbra 2006}

